\title{
Analysis of the type 2 diabetes gene, TCF $7 L 2$, in 13,795 type 1 diabetes cases and control subjects
}

\author{
S. F. Field • J. M. M. Howson • D. J. Smyth • \\ N. M. Walker $\cdot$ D. B. Dunger $\cdot$ J. A. Todd
}

Received: 2 August 2006 / Accepted: 2 October 2006 /Published online: 25 October 2006

(C) Springer-Verlag 2006

To the Editor: The two most common forms of diabetes that have been classified are type 1 diabetes and type 2 diabetes. Type 1 diabetes is characterised by infiltration of the pancreas by autoreactive $T$ cells and autoimmune destruction of pancreatic beta cells, leading to a complete loss of insulin production, whereas type 2 diabetes is associated with the gradual increase of insulin insensitivity in tissues leading to hyperglycaemia and beta cell failure. However, it has been suggested that type 1 diabetes and type 2 diabetes may share a common genetic aetiology [1]. For example, the accelerator hypothesis suggests that type 1 diabetes and type 2 diabetes are the same disease of hyperglycaemiainduced beta cell damage but that type 1 diabetes has the added effect of autoimmunity [1].

One way of testing the hypothesis that there is a common causal pathway between type 1 and type 2 diabetes is to analyse a type 2 diabetes gene with a large effect in a large type 1 diabetes sample. Until very recently [2] this has not been possible, as no such locus has emerged from type 2 diabetes genetics studies. Recently, however, the transcription-factor-7-like 2 (TCF7L2) gene region on

S. F. Field · J. M. M. Howson • D. J. Smyth · N. M. Walker •

J. A. Todd $(\square)$

Juvenile Diabetes Research Foundation/Wellcome Trust Diabetes and Inflammation Laboratory, Cambridge Institute

for Medical Research, University of Cambridge,

Wellcome Trust/MRC Building, Addenbrooke's Hospital,

Hills Road, Cambridge CB2 2XY, UK

e-mail: John.Todd@cimr.cam.ac.uk

D. B. Dunger

Department of Paediatrics, University of Cambridge,

Addenbrooke's Hospital,

Cambridge, UK chromosome 10q25.2 has been found to contribute substantially to the risk of type 2 diabetes with convincing statistical support (relative risk $[\mathrm{RR}]=0.67 ; p=2.1 \times 10^{-9}$ for the 0 allele of the microsatellite marker DG10S478) [2]. This study was carried out in three different populations: Icelandic, Danish and white American. Two single nucleotide polymorphisms (SNPs) were also genotyped in this study: rs12255372 (G>T, minor allele frequency [MAF] 0.36 in control subjects) and rs7903146 (C $>\mathrm{T}, \mathrm{MAF}=0.28$ in control subjects). rs12255372 was found to be in high linkage disequilibrium (LD) with DG10S478 $\left(r^{2}=0.95\right.$ for the major $\mathrm{G}$ allele of the SNP with the 0 allele of the microsatellite marker). rs7903146 was in lower LD with the DG10S478 $\left(r^{2}=0.75\right)$ : for the minor allele (T) of this SNP the authors obtained odds ratios (ORs) of 1.41-1.71 in the three populations and $p$ values from 0.0018 to $1.6 \times 10^{-9}$ [2]. These results were independently replicated in 2,158 white UK type 2 diabetic subjects, 2,574 geographically matched white control subjects and 388 parent-offspring trios [3]. In this population it was found that the $\mathrm{T}$ allele of rs7903146 was the most associated with type 2 diabetes susceptibility $(\mathrm{OR}=1.36,95 \% \mathrm{CI}=1.24-1.48$ and $p=3.6 \times$ $10^{-10}, \mathrm{MAF}=0.31$ in control subjects), but that the $\mathrm{T}$ allele of $\mathrm{rs} 12255372$ was also associated $(\mathrm{OR}=1.29,95 \% \mathrm{CI}=$ $1.18-1.41 ; p=2.2 \times 10^{-6}, \mathrm{MAF}=0.30$ in control subjects) [3]. These results have also been confirmed by other studies in Finnish and US populations [4, 5]. A study on type 2 diabetes progression suggests that TCF7L2 may be associated with insulin secretion [6].

Therefore, as $T C F 7 L 2$ is a major gene in type 2 diabetes we can now test if it affects type 1 diabetes susceptibility. We analysed the two SNPs, rs12255372 and rs7903146, in 6,199 white UK type 1 diabetic subjects (5,872 from the Juvenile Diabetes Research Foundation/Wellcome Trust Diabetes and Inflammation Laboratory's Genetic Resource 
Investigating Diabetes study (http://www-gene.cimr.cam.ac. uk/ucdr/grid.shtml) and 327 from the Oxford Regional Prospective Study [7]) and 7,596 geographically matched white control subjects (from the 1958 British Birth Cohort [8]) using TaqMan 5' nuclease assay (Applied Biosystems, Warrington, Cheshire, UK). All type 1 diabetic subjects were diagnosed under the age of 17 years. Given the reported MAF of 0.30 (in a sample set from the 1958 British Birth Cohort [3]), our study has $80 \%$ power to detect an effect with an OR as low as 1.12 at $\alpha=10^{-3}$. This $\alpha$ level can be considered appropriate assuming that the prior information about common genetic and mechanistic pathways in type 2 diabetes and type 1 diabetes is true. Alternatively, assuming no prior information, on a genomewide level, $\alpha=10^{-8}$, our study has $80 \%$ power to detect an effect with an OR as low as 1.19. In this sample set we obtained a $\mathrm{MAF}=0.29$ for the $\mathrm{T}$ alleles of both $\mathrm{rs} 12255372$ and rs7903146. The genotype distributions for both of these SNPs were consistent with Hardy-Weinberg equilibrium in the control subjects $(p>0.05)$. We found no evidence for association between TCF7L2 and type 1 diabetes: for rs12255372, $\mathrm{OR}=0.96$ and $p=0.17$, and for rs7903146, $\mathrm{OR}=0.99$ and $p=0.79$, for the minor $\mathrm{T}$ alleles of both SNPs (Table 1).

Table 1 Association of TCF7L2 SNPs rs12255372 and rs7903146 with type 1 diabetes in 6,199 type 1 diabetic subjects and 7,596 control subjects

\begin{tabular}{|c|c|c|c|c|}
\hline & $\begin{array}{l}\text { Diabetic } \\
\text { subjects (\%) }\end{array}$ & $\begin{array}{l}\text { Control } \\
\text { subjects (\%) }\end{array}$ & OR & $95 \% \mathrm{CI}$ \\
\hline \multicolumn{5}{|c|}{ rs 12255372} \\
\hline \multicolumn{5}{|c|}{ Alleles ( $2 \times$ number of subjects), $p=0.17$} \\
\hline G & $8,561(0.72)$ & $10,461(0.71)$ & 1.00 & (reference) \\
\hline $\mathrm{T}$ & $3,377(0.28)$ & $4,279(0.29)$ & 0.96 & $0.91-1.02$ \\
\hline \multicolumn{5}{|c|}{ Genotypes (number achieved), $p=0.33$} \\
\hline $\mathrm{G} / \mathrm{G}$ & $3,033(0.51)$ & $3,687(0.50)$ & 1.00 & (reference) \\
\hline $\mathrm{T} / \mathrm{G}$ & $2,495(0.42)$ & $3,087(0.42)$ & 0.97 & $0.91-1.05$ \\
\hline $\mathrm{T} / \mathrm{T}$ & $441(0.07)$ & $596(0.08)$ & 0.90 & $0.79-1.03$ \\
\hline \multicolumn{5}{|c|}{ rs 7903146} \\
\hline \multicolumn{5}{|c|}{ Alleles $(2 \times$ number of subjects $), p=0.79$} \\
\hline $\mathrm{C}$ & $8,404(0.71)$ & $10,306(0.71)$ & 1.00 & (reference) \\
\hline $\mathrm{T}$ & $3,400(0.29)$ & $4,224(0.29)$ & 0.99 & $0.94-1.05$ \\
\hline \multicolumn{5}{|c|}{ Genotypes (number achieved), $p=0.84$} \\
\hline $\mathrm{C} / \mathrm{C}$ & $2,991(0.51)$ & $3,669(0.50)$ & 1.00 & (reference) \\
\hline $\mathrm{T} / \mathrm{C}$ & $2,422(0.41)$ & $2,968(0.41)$ & 1.01 & $0.93-1.08$ \\
\hline $\mathrm{T} / \mathrm{T}$ & $489(0.08)$ & $628(0.09)$ & 0.97 & $0.85-1.10$ \\
\hline
\end{tabular}

These data do not support a model of a shared major causal pathway in type 2 diabetes and type 1 diabetes. However, as more and more causal variants for common multifactorial diseases are established they will provide a panel of markers that can be used to elucidate the functions and physiology of other diseases. Thus, in this study, we have found that a variant that increases the risk for type 2 diabetes [2-5] and may affect insulin secretion [6] does not alter susceptibility to the immune-mediated destruction of beta cells in type 1 diabetes to any measurable extent in this British population.

Acknowledgements This work was funded by the Wellcome Trust, the Juvenile Diabetes Research Foundation and the Medical Research Council. We acknowledge use of DNA from the 1958 British Birth Cohort collection (D. Strachan, S. Ring, W. McArdle and M. Pembrey), funded by the Medical Research Council grant G0000934 and Wellcome Trust grant 068545/Z/02, and thank P. Burton for help. We also thank H. Stevens and the Diabetes and Inflammation Laboratory DNA team for their help in preparing the samples.

Duality of interest The authors have no duality of interest in regard to this study.

\section{References}

1. Wilkin TJ (2001) The accelerator hypothesis: weight gain as the missing link between type I and type II diabetes. Diabetologia 44:914-922

2. Grant SF, Thorleifsson G, Reynisdottir I et al (2006) Variant of transcription factor 7-like 2 (TCF7L2) gene confers risk of type 2 diabetes. Nat Genet 38:320-323

3. Groves CJ, Zeggini E, Minton J et al (2006) Association analysis of 6,736 U.K. subjects provides replication and confirms TCF7L2 as a type 2 diabetes susceptibility gene with a substantial effect on individual risk. Diabetes 55:2640-2644

4. Scott LJ, Bonnycastle LL, Willer CJ et al (2006) Association of transcription factor 7-like 2 (TCF7L2) variants with type 2 diabetes in a Finnish sample. Diabetes 55:2649-2653

5. Zhang C, Qi L, Hunter DJ et al (2006) Variant of transcription factor 7-like 2 (TCF7L2) gene and the risk of type 2 diabetes in large cohorts of U.S. women and men. Diabetes 55:2645-2648

6. Florez JC, Jablonski KA, Bayley N et al (2006) TCF7L2 polymorphisms and progression to diabetes in the Diabetes Prevention Program. N Engl J Med 355:241-250

7. Amin R, Bahu TK, Widmer B et al (2005) Longitudinal relation between limited joint mobility, height, insulin-like growth factor 1 levels, and risk of developing microalbuminuria: the Oxford Regional Prospective Study. Arch Dis Child 90:1039-1044

8. Power C, Elliott J (2001) Cohort profile: 1958 British birth cohort (National Child Development Study). Int J Epidemiol 35:34-41 